\title{
COMPUTER MEDIATED DISCOURSE AND TURN TAKING DEVICES
}

\author{
Šárka Ježková
}

\begin{abstract}
The article attempts to show how turn taking strategies of using particular devices in asynchronous forums differ from face-to-face communication, how they are conditioned by the medium and also how they are influenced by the aim of a particular discussion. The analysis, as part of bigger research, is based on comparison of two corpora of online discussions with different topics and aims, and it shows the shift of functions of typical written devices such as titles, greetings, etc. It is evident that even if interactive exchanges in asynchronous computer mediated forums tend to be linked together less tightly than in face-to-face communication, the potential confusion is prevented by adopting compensatory strategies.
\end{abstract}

\section{Key words}

computer mediated discourse (CMD), asynchronous communication, learners's language, addressing strategies, adjacency pairs, informative and emotional functions of discourse

\section{Introduction}

The discourse of asynchronous computer on-line forums has usually been considered a mixture of features which are typical of speech and writing. Authors quite frequently look for an appropriate descriptive term of a new form of communication. Thus we can encounter labels like e-style, written speech, spoken text and many other attempts to find an appropriate title expressing that the two types of text are somehow mixed together (Biber 1995, Baron 2000, Crystal 2001). If we apply the seven criteria introduced by Crystal to distinguish between spoken and written discourse, four of them are not relevant here because they are not decisive enough and they depend very significantly on the particular type of communication: spontaneous vs. contrived reaction of a participant; loosely vs. elaborately structured message; primary purpose of the communication is socially interactive vs. factually communicative; the message is immediately vs. repeatedly revisable (Crystal 2001: 43). The following three criteria suggest that the explored texts are samples of written-like communication because: asynchronous chats are space bound and not time bound; they are not face-toface, but visually decontextualized; they are/or can be relatively graphically rich, but they cannot be prosodically rich (if we strictly distinguish between 
the channel of perception: sight or hearing). Even though the application of the above-mentioned criteria suggests that the texts have more features typical for written language, in reality they look more like a speech (Baron 2003: 104). Also Biber suggests that "no absolute spoken/written distinction is identified in the study, rather the relations among the spoken and written texts are complex and associated with a variety of different situational, functional and processing considerations" (Biber 1995: 25).

Moreover, particular realizations of both written and spoken texts can differ significantly. As Urbanová (2003: 20) admits the range of spoken texts is very wide regarding their length, number of participants, private vs. public purpose, etc. Also if we consider the variety of electronic texts, their purpose, length and other characteristic features can differ remarkably.

The primary aim of this study is to assess where the language of asynchronous on-line forums proves the characteristic features of spoken communication and where of written communication. The analysis is mainly focused on the influence of the lack of time boundness on the use of particular strategies to create obvious adjacency pairs. In other words, the distribution of direct personal addresses is examined with the aim to determine the factors influencing the choice of various combinations of addresses. Since the language corpora of two different forums (with different primary purposes) are compared, the main attempt is focused on identifying the most distinct influences on the distribution of direct addressing links, among which the degree of informativeness vs. the degree of emotiveness seems to be the most powerful.

\section{Functional segments in messages}

In messages, it is possible to identify a few relatively stable segments, which show a tendency to follow a repeating principle. Herring (1996: 86) argues that some parts are derived from the pre-computer communication and are based on letter-communication strategies. Every message can be thus divided into a title and five "macrosegments" (i.e. opening - salutation/greeting, introduction, body, close, signature); however, it does not mean that every single message has to comprise all the parts.

Usually a message starts with a title, whose function has been shifted in computer mediated communication (CMC) as it will be proved later in the analysis. It can often be observed that not all messages express the title overtly. It seems that the strategy not to include the title reflects the shift of the character of CMC more towards the character of spoken communication (in conversation participants do not need to repeat the topic in every turn). The following part is an 
opening, which represents one of the remainders of the "letter-communication" period and there are quite rigid patterns, even though nowadays they are more and more frequently modified according to the spoken discourse patterns. The next part is an introduction, whose primary function is to link the message to previous message(s). The contentful body of a message represents the informationally heaviest part of a message - an author can express his/her view, provide or request information, express feelings, suggest solution, etc. The variety of combinations is highly dependent on the overall purpose of the forum. After the body, there is usually a close - another type of link (similar to introduction) - which expresses an appeal to other participants and encourages the subsequent reactions. The last part of a message is again (similarly to opening) based on epistolary conventions and its informational value is rather low (Herring 1996).

In any part of a message we can find interconnections with the previous or following messages in a forum. From the following analysis of CMC texts, it is evident that the density of links and their combinations depend very much on the stream and purpose of communication. It should also be noted that not all the segments must be found in every message. Very easily we can find contributions without a greeting, without an introduction or without a closing, even without a signature, which again seems to bring CMC closer to the faceto-face communication. In such discussions participants usually do not have to face the situation which is sometimes called distribution problem in multiparticipant conversation (i.e. how a speaker knows when it is his/her turn, how he/she knows when it is time to finish the talk, what helps them to manage the conversation with minimal gap and minimal overlap) (Schiffrin 2008: 238). Paradoxically, the direct reaction to certain initiation may be easier in CMC than in face-to-face conversation because when participants perceive the time delay as a communication barrier, they feel obliged to express the direct link to the first part of the pair and thus the adjacency is more obvious.

\section{Factors influencing the discourse}

As mentioned above, a lot of linguistic studies revealed the fact that there is a "lack of an absolute difference between speech and writing" (Biber 1995: 161) and so one seemingly significant feature of written or spoken character can be overridden by other situational characteristics. There is "a complex of relationships between language forms and contexts of use, certainly not a simple division between written and spoken media" (McCarthy \& Carter 1994: 9). Moreover, sometimes the typical features (either spoken or written) are defined with regard to one criterion only. For example, Widdowson contrasts the two 
types of texts: "participants in spoken interaction produce and process the text as they go along and there is no need to be retained ... and written text is designed and recorded unilaterally in the act of production by one of the participants as a completed expression of the intended message" (Widdowson 2007: 7). However, there are many instances where such criteria can function vice versa.

If we consider the asynchronous $\mathrm{CMC}$ in relation to face-to-face communication, the first difference is the lack of simultaneous feedback; unlike the real-time conversation it is not time-bound so the expected consequence would be some sort of compensation strategy (e.g. more frequent direct links to the previous or following messages). Another factor which is interrelated with the previous one and which definitely also influences the flow of communication in asynchronous forums is much slower rhythm of interaction (frequent timedelays or lags) and disrupted turn adjacency compared to the face-to-face communication (Herring 1999). Although the results of the following analysis have not been compared to any particular corpus of face-to-face communication, the deviations were not significant enough so that they could suggest any general shift of communication strategies.

Also e-mail communication, as one of the types of CMC which has some common features with asynchronous discussion and which differs from it as well (in most cases in terms of number of participants) is often considered "closer to characteristics of the spoken mode than to the written one" (Comorek 2007: 27). Although he relates the major criteria distinguishing between the spoken and written mode mainly to the notion of grammaticality, his final assumption can be agreed on. It is supported by the opinion that "online interaction overwhelmingly takes place by means of discourse; that is, participants interact by means of verbal language, usually typed on a keyboard and read as text on a computer screen" (Herring 2004: 338).

\section{Language material analysed}

The analysed language material has been collected from two asynchronous forums accompanying students' work on two different projects during their long-term teaching practice. The software tool, Matforum, was developed for the purpose of on-line communication among students during that period, with various aims of different types of interaction (Černá 2005). All of the participants were Czech native speakers, they studied English as a foreign language and they were future English teachers with the level of English of C1-C2 of the Common European Framework of Reference. 
The size of corpora is quite comparable - about ten thousand words (9,300 words vs. 10,400 words), the participants in both discussions are identical (11 female and 1 male); only the periods for which the forums were opened differ ( 9 weeks vs. 15 weeks), and the number of contributions is surprisingly different (62 messages vs. 162 messages), which in the end does not influence the final findings much since the size of the corpus is quite similar.

Most of the characteristic features of both discussions are quite similar except the overall aims of the forums. The goal of ELT Curriculum discussion forum was to discuss the topic while the goal of HotPotatoes forum was to provide peer support and help students while working with authoring software and creating interactive multimedia exercises. The purpose was always stated in the very first message posted by a tutor at the beginning of the forum. The ELT Curriculum Forum was opened with instructions using key words like: inform your colleagues, state some specifics, think about the documents, etc. and the HotPotatoes Forum such as help each other, share the experience, enable them to learn, provide feedback, etc. Later in the analysis it will be argued that this was probably the crucial factor playing a very important role and influencing the use of different strategies of creating links between adjacency pairs in these forums. It should also be stated here that only the overtly expressed links are taken into consideration in this research, although I am aware of a wide scale of potential indirect connections, but since indirectness is quite difficult to measure and interpret (Thomas 1995: 134), the potential instances of indirect addresses are not included in this initial stage of the research.

\section{Devices expressing adjacency pairs and ways of addressing participants}

The multi-participant communication naturally employs devices to join adjacency pairs where it is necessary to express any direct connections. It should be noted that even in synchronous face-to-face discussions it is sometimes difficult to follow the thread of initiations and reactions or replies to them. So in this asynchronous electronic discussion, it can be generalised that there are three basic message segments (see Section 2) where the participants express some kind of direct connection to a selected previous message: a) title of the message, b) opening greeting c) introduction or body of a message. Even though we can trace quite a lot of features which are typical of face-to-face communication, there is a lack of non-verbal communication means, which possibly motivates the distribution of some other devices. As Biber (1995: 161) states "the lack of an absolute difference between speech and writing shows that it is possible, within each mode, to override the salient situational characteristics of the mode". 
The study proved the shift of the function of greeting from face-to-face communication to electronic communication. More than twenty years before this research Coulthard (1985: 88) suggested that the function of a greeting was almost invariant and it had a fixed position in a conversation. Nowadays, however, the development of new media has changed significantly the function of some devices which were traditionally considered as either spoken or written, and greeting is one of them. Unlike in face-to-face conversation, where it still has quite conventional position and function, in $\mathrm{CMC}$ it can be a formal opening according to epistolary conventions but it can also adopt some new functions which were originally performed by other means. One of the noticeable new functions is to establish a direct link to a previous message and create adjacency pair.

The total proportion of messages using any sort of direct addresses is very similar in both types of chats as it could be seen in Table 1. Only in one third of messages, the participants felt the need to express the direct connection to one particular contribution. So the results suggest that the overall communication strategies of turn taking in both forums are very similar.

\begin{tabular}{|l|c|c|c|}
\hline Type of forum & Messages with direct address & Total number of messages & Ratio \\
\hline $\begin{array}{l}\text { ELT Curriculum } \\
\text { Forum }\end{array}$ & 20 & 62 & $32 \%$ \\
\hline HotPotatoes Forum & 61 & 162 & $38 \%$ \\
\hline
\end{tabular}

Table 1: Messages with direct addressing

However, if we compare the distribution of the three major types of linkage, there is a significant difference between the two discussions, which may be motivated by the different purposes of the forums (Table 2). In ELT Curriculum Forum, where the major aim was to discuss the topic, about two thirds of any links were realised in the core of a message (i.e. introduction or body). Students did not need to express the connection in the title or greeting, which are the opening parts of the message and mostly are very general, but they referred to a particular preceding message in the body, when they wanted to discuss a certain aspect of ELT Curriculum mentioned before.

On the other hand, almost two thirds of direct links expressed in HotPotatoes Forum, with its primary goal of peer support, were realised in the title and/or greeting, i.e. the first possible moment to signal the direct connection. Keeping in mind that there were identical participants in both forums, we could explain the different communication strategies by the different goals of chats. In ELT Curriculum it was primarily the topic discussion, in the HotPotatoes it was a 
social interaction above all. Thus the same students chose different strategies in the situations when they felt they should connect their contribution to one single previous message. When their primary intention was to support one particular participant in his/her difficulties or help him/her with some technical problem, students addressed him/her at the very beginning of a message, i.e. in the title, in the greeting, or in both. On the contrary, when the primary intention was to discuss certain aspect(s) of ELT Curriculum, they used general links in titles and greetings, and only at the point of discussion when they referred to one particular previous contribution, they decided to use direct personal link in the body of a message.

\begin{tabular}{|l|c|c|c|c|c|c|}
\hline Type of forum & \multicolumn{2}{|c|}{ Title } & \multicolumn{2}{c|}{ Greeting } & \multicolumn{2}{c|}{ Link } \\
\hline ELT Curriculum Forum & 5 & $23 \%$ & 2 & $9 \%$ & 15 & $68 \%$ \\
\hline HotPotatoes Forum & 20 & $26 \%$ & 27 & $35 \%$ & 30 & $39 \%$ \\
\hline
\end{tabular}

Table 2: Distribution of all direct personal addressing

The most striking difference between the two chats consists in the distribution of various combinations of direct links to the previous messages, summarised in Table 3. While the ELT Curriculum Forum shows a tendency to express a direct address only once, most of the occurrences in the body of a message (only in two messages we can find double link), in the HotPotatoes Forum one quarter of contributions use more than one direct link.

\begin{tabular}{|l|c|c|c|c|c|c|c|}
\hline $\begin{array}{l}\text { Type of } \\
\text { forum }\end{array}$ & $\begin{array}{c}\text { Title } \\
\text { only }\end{array}$ & $\begin{array}{c}\text { Greeting } \\
\text { only }\end{array}$ & $\begin{array}{c}\text { Body } \\
\text { only }\end{array}$ & $\begin{array}{c}\text { Title } \\
\text { +greeting }\end{array}$ & $\begin{array}{c}\text { Title } \\
\text { +body }\end{array}$ & $\begin{array}{c}\text { Greeting } \\
\text { + body }\end{array}$ & $\begin{array}{c}\text { Title + greeting } \\
\text { + body }\end{array}$ \\
\hline $\begin{array}{l}\text { ELT } \\
\text { Curriculum } \\
\text { Forum }\end{array}$ & 3 & 2 & 13 & 0 & 2 & 0 & 0 \\
\hline $\begin{array}{l}\text { HotPotatoes } \\
\text { Forum }\end{array}$ & 6 & 14 & 26 & 11 & 2 & 1 & 1 \\
\hline
\end{tabular}

Note: For easier orientation, all the direct addresses occurring later than in the title or greeting are summarised under the cover term "body".

Table 3: Combinations of direct personal addressing

In HotPotatoes Forum, there is quite a significant number of one type of direct addressing combination (title + greeting), which, according to Crystal (2001), is not probable to happen. "The existence of personal and interactive elements in titles means that they take on some of the character of a greeting. We would not 
expect a message titled 'Response to Jeff' to begin 'Dear Jeff' or 'Hi Jeff'. The link has already been made" (Crystal 2001: 140).' It seems that if the primary purpose of the forum is the social support of the other members of the group, the participants tend to address the particular person more than once and as early as possible - even against the above-mentioned principle. Typical combinations are illustrated in (1), (2) and (3), where the title and greeting comprise a direct link and the introduction includes only a general link.

(1) to Mxxx / hello Mxxx / I used my name and surname ... (HP 10, B2)

(2) to $\mathrm{pxxx} /$ hello $\mathrm{pxxx} / i$ think that it is quite satisfactory ... (HP 101, F19)

(3) for Kxxx / Hi Kxxx / I cannot open the reading exercise ... (HP 149, I20)

Multiple addressing is typical for HotPotatoes Forum, which again supports the idea that when the overall aim of the forum is to create the collaborative atmosphere of the group and to support the people with troubles, the number of direct addresses increases and it brings a feeling of real personal assistance like in face-to-face conversation.

Most frequent single connections in both forums are realised in a body of a message, which signals that in such cases usually not the whole message, but only a part of it reacts to one single previous contribution. It may be the reason why the link is not in the title or greeting, but later in the message when it concerns a particular aspect which was mentioned by another person before. Such instances are found in both forums, as exemplified in (4) to (7).

(4) RVP ZS / Hi everyone / ... I pretty much share the same feelings as Sxxx ... (ELT 25, E4)

(5) differences between classes / hello / as Mxxx wrote ... (ELT 34, K3)

(6) IT room / Hello / I have similar problem as Lxxx ... (HP 52, B7)

(7) website / Hi everyone / Dxxx is right ... (HP 83, D11)

The distribution of direct links in titles and greetings displays a noticeable difference. In HotPotatoes Forum, the greeting quite frequently adopts the function of a direct link to a previous message (either separately, or in connection with other segments), on the contrary, in ELT Curriculum Forum, it is the title that is used more frequently as a direct link (again either on its own, or in combination with the link in the body). The examples (8) and (9) illustrate the preference for greetings in HotPotatoes Forum, and contributions (10) and (11) exemplify the tendency in ELT Forum. 


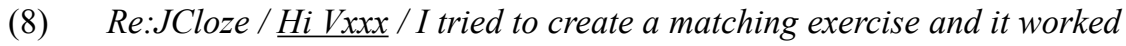
well ... (HP 16, D2)

(9) website / Hello Mxxx / I think that the website will be given to us some time later... (HP 82, C8)

(10) to Lxxx / Hi / I must admit that I also have mixed feelings about SEP ... (ELT 14, C2)

(11) $\underline{T x x x} /$ Hi everyone / I am glad to hear that we quite agreed on the fact that ... (ELT 19, E2)

The types of titles used in both corpora show that this segment mostly keeps its primary function, similar for example to e-mail communication, where it introduces a topic or refers back to a topic which was discussed already (i.e. RVP ZS, SEP as an opportunity, JCross, Uploading, Re: CLIL, Re: technical problems). Even in the contributions where it establishes a direct reference to one particular message, in principle it is done through the topic, not through the person who sent the message (i.e. Re: Text for celebrities, Re: School in Pxxx). Only a few contributions contain a direct address right in the title, and if so, the link is frequently repeated once more later in another segment.

The functions of greeting in such CMC are slightly shifted, compared to faceto-face conversation. In most contributions, a greeting plays a formal opening function according to written correspondence conventions. But unlike in paper letters or e-mail messages, it has a very general form since a participant wants to address the whole group (i.e. Hello everybody, Hi all, Dear colleagues) or he/she uses greeting only and no address (i.e. Hello, Hi, Hello again). Where the personal address is used, it shows a direct link to a previous contribution or/and it appeals to one particular person directly, usually also expressing positive emotions of compassion. The comparison of the two corpora shows that the more the forum is oriented towards the social interaction, the more frequently participants decide to address one single person directly. This can also be understood as a tendency to communicate in a way more similar to face-to-face conversation. Moreover, in both discussions we can find some contributions that do not comprise any greeting at all, which again proves that this type of CMC copies the real personal conversation.

Direct links used in the segment of introduction or body of a message (cover term "body" used in Table 3) remarkably prevail in the forum focused on the discussion of a topic. In such a discussion, a title mostly refers to the overall topic or introduces the school of a contributor (i.e. The educational programme of the basic school $x x x$ in $x x x$, SEP of Z $\check{S} x x x, \check{S} V P-Z \check{S} x x x)$ and a greeting addresses the whole group, but when a particular aspect of ELT Curriculum concerns another previously posted message, a participant often decides for 
a direct personal address so that he/she makes a straightforward reference and prevents a confusion or misunderstanding.

The following extract represented by sentences (12) to (19) shows that in the flow of discussion participants use all the combinations.

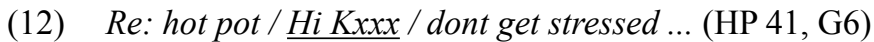

(13) to Kxxx / HiKxxx / I also think that we sould not use JMix ... (HP 42, B6)

(14) Re: to Kxxx and Pxxx / Hi / I am also confused concerning the usage of JMix ... (HP 43, G7)

(15) To Kxxx and Pxxx / Hello / I am also not sure about using JMix ... (HP 44, G8)

(16) Final choice / Hello everybody / ... (HP 45, G9)

(17) to everybody / $\mathrm{Hi} / \ldots$ (HP 46, C4)

(18) hot pot / hello / thank you Pxxx and Vxxx for your reply :) ... (HP 47, F6)

(19) to Dxxx and others / Hello :-) / I do not think that we are supposed ... (HP 48, I7)

\section{Conclusion}

Asynchronous $\mathrm{CMC}$ has been considered rather interactionally incoherent mostly due to the delayed nature of discussions (Herring 2008). However, the study described in this article shows that even though turn taking strategies in asynchronous forums differ from face-to-face communication and they are conditioned by the specificity of the communication medium, participants of such discussions adopt procedures compensating the temporal delays and preventing potential misinterpretations. It also reveals that the use of particular devices depends on the overall design of asynchronous on-line forum and that the principles typical for oral communication (such as "no gap - no overlap" and sequential coherence) are frequently violated (Herring 1999: 4). At the same time, it proves that asynchronous CMC cannot be viewed as a blend of written and spoken features, but rather as a new phenomenon, at some moments demonstrating features closer to writing, at others features closer to speech. The findings of the analysis are also in accordance with the view of Baron (2003: 103), who points out that the language of various types of CMC is developing so quickly so that it is difficult to describe their features exhaustively and finally.

The comparison of two corpora of on-line asynchronous discussions with different topics and aims shows the shift of functions of some structures which have been considered typically written, or typically spoken (e.g. titles, greetings). It is evident that the degree of incoherence caused by disrupted adjacency and 
overlapping exchanges is not perceived as disturbing and seems to be quite common in asynchronous $\mathrm{CMC}$, because there are other means used in order to overcome the difficulties concerning interactional management. Even though interactive exchanges in asynchronous $\mathrm{CMC}$ tend to be linked together less tightly than face-to-face communication, especially due to the lack of temporal boundness and lack of non-verbal communication features, the potential confusion is prevented by adopting compensatory strategies (Herring 1999: 9).

To sum up the findings of the exploration, some features disclosed by the analysis are common in both forums regardless of their aim and focus. Mostly it concerns the shifted functions of certain segments and structures. A greeting has a different function from the one typical of conversation - it is not the opening move, but it sets the link within adjacency pairs, or it serves just as a conventional opening of a message. Also a title of a message can adopt the function of creating an adjacency pair and include direct address. Even though such a strategy is not dominant, it shows another direction of changes.

Some other features are distributed differently in the two corpora and they prove that the type and placement of a direct personal address depend on the purpose of an electronic discussion (topic oriented, where content discussion is prevailing, vs. social interaction oriented, where support of the group members is prevailing). Generally, direct addresses can occur in various segments of a message and also they can occur in various combinations. But there is a significant difference in the choice of strategies between the forums. While in the HotPotatoes Forum participants tend to express the personal link at the very beginning of a message: in a title or greeting, or even in both of these segments; in the ELT Curriculum Forum they use a direct address later in the body when they discuss the aspect that somebody else mentioned before. Even though in both corpora about one third of all messages contain some type of direct address, there are noticeable differences in the preference for particular type or combination. In ELT Curriculum Forum about two thirds of all the links are realised in the segment of body, but in HotPotatoes Forum two thirds are realised in the segment of title or greeting. While in ELT Curriculum Forum there is a strong tendency to address directly only once in a message, in HotPotatoes Forum about one quarter of messages contain more than one direct personal address. It can be concluded that the use of certain strategies in one discussion and some others in the second is influenced by the primary purpose of such communication. Similarly Urbanová (2003: 36) stresses how significantly the communication can differ if either emotiveness prevails or informativeness prevails. In ELT Curriculum Forum, the prevalence of messages whose primary aim is to inform is obvious, and on the other hand in HotPotatoes Forum, the messages expressing emotions (positive support or attitudes) are very frequent. 
The findings of the analysis mentioned above serve as a starting point of a more extensive and complex research of learners' language from the point of view of specificity of CMC and also from the point of view of second language acquisition. The focus of this study was restricted to the adjacency pairs compensatory strategies of creating obvious direct links to the messages backwards and the whole analysis will be supplemented by the research concerning the use of other turn taking devices in asynchronous multi-participant computer communication.

\section{References}

Baron, N. S. (2000) Alphabet to Email: How Written English Evolved and Where It's Heading. London: Routledge.

Baron, N. S. (2003) 'Why email looks like speech: Proofreading, pedagogy, and public face.' In: Aitchison J. and Lewis D. (eds) New Media Language. London: Routledge. 102-113.

Biber, D. (1995) Variation across Speech and Writing. New York: Cambridge University Press.

Comorek, J. (2007) 'E-mail - a bridge between written and spoken mode \& strategy of beginnings.' Topics in Linguistics 1. 27-29.

Coulthard, M. (1985) An Introduction to Discourse Analysis. Harlow: Pearson Education.

Crystal, D. (2001) Language and the Internet. Cambridge: Cambridge University Press.

Černá, M. (2005) ICT in Teacher Education: Extending Opportunities for Professional Learning. Pardubice: Univerzita Pardubice.

Herring, S. C. (1996) 'Two variants of an electronic message schema.' In: Herring, S. C. (ed.) Computer-Mediated Communication: Linguistic, Social and Cross-Cultural Perspectives. Amsterdam: John Benjamins. 81-106.

Herring, S. C. (1999) 'International coherence in CMC.' Journal of Computer-Mediated Communication 4(4). http://jcmc.indiana.edu/vol4/issue4/herring.html, retrieved March 25, 2009.

Herring, S. C. (2004) 'Computer-mediated discourse analysis: An approach to researching online behavior.' In: Barab, S. A., Kling, R. and Gray, J. H. (eds) Designing for Virtual Communities in the Service of Learning. New York: Cambridge University Press. 338-376.

Herring, S. C. (2008) 'Computer-mediated discourse.' In: Schiffrin D., Tannen D. and Hamilton H. E. (eds) The Handbook of Discourse Analysis. Oxford: Blackwell Publishers. 612-634.

McCarthy, M. and Carter, R. (1994) Language as Discourse: Perspectives for Language Teaching. London: Longman.

Schiffrin, D. (2008) Approaches to Discourse. Oxford: Blackwell Publishers.

Thomas, J. (1995) Meaning in Interaction: An Introduction to Pragmatics. Essex: Longman Group Limited.

Urbanová, L. (2003) On Expressing Meaning in English Conversation: Semantic Indeterminacy. Brno: Masarykova univerzita v Brně.

Widdowson, H. G. (2007) Discourse Analysis. Oxford: Oxford University Press.

\section{Sources}

ELT Curriculum - e-conference. http://matforum.upce.cz, retrieved March 23, 2009

HotPot Conference. http://matforum.upce.cz, retrieved March 24, 2009 